\title{
An introduction to genetic and epigenetic changes in prostate gland - implications in efficacy of phytotherapy of benign prostatic hyperplasia and prostate cancer
}

\author{
Joanna Bartkowiak-Wieczorek', Radosław Kujawski ${ }^{2}$ Anna Bogacz'1, 2 , Marcin Ożarowski 3 \\ 1. Laboratory of Experimental Pharmacogenetics, Department of Clinical Pharmacy and Biopharmacy, Poznan University \\ of Medical Sciences, Poland \\ 2. Department of Pharmacology and Phytochemistry, Institute of Natural Fibers and Medicinal Plants, Poznan, Poland \\ 3. Department of Pharmaceutical Botany and Biotechnology, Poznan University of Medical Sciences, Poland
}

\begin{abstract}
The usage of classical pharmacological treatment of prostate diseases causes the risk of a number of side effects therefore the researchers are looking for new pharmacologically active molecules, including those contained in the plant extracts. The most widely studied is the lipido-sterolic extract from Serenoa repens (saw palmetto), water extract from Camellia sinensis (green tea) and several cruciferous vegetables. The molecular mechanisms underlying of the development and the progression of prostate disorders, especially benign prostatic hyperplasia (BPH) and prostate cancer (PC), remain still poorly understood. The development of pathologically changed prostate cells proliferation involves many factors, including genetic alterations, such as mutations, and epigenetic changes, appear to contribute to the transformation and progression of prostate cancer. In this paper we suggest that the knowledge of epigenetic modifications presented in this paper introduces the new point of view concerning the possibility of action of plant substances used in prevention and symptomatic treatment of BPH and prostate cancer. Thus, identification of the epigenetic modifications involved on the one hand in the development and progression of BPH / PC, on the other influencing the efficacy and safety of potential phytotherapeutics will be helpful in identifying its novel therapeutic strategy.
\end{abstract}

Keywords: prostate disorders, phytotherapy, epigenetic modifications.

\section{Introduction}

An efficient pharmacotherapy of prostate diseases, especially benign prostatic hyperplasia (BPH) and prostate cancer (PC), are extremely important aspects of the modern medicine because of the increasing number of illnesses as a result of the increase in life expectancy and the fact of aging of population [Cohen and Rokhlin, 2009].

Prostate cancer is a common illness, which leads to death among men all over the world [Cohen and Rokhlin, 2009]. The molecular mechanisms underlying of the development and the progression of prostate cancer remains still poorly understood. Genetic alterations, such as mutations, and epigenetic changes, defined as heritable changes in gene expression that occur without changes in DNA sequence, appear to contribute to the malignant transformation and progression of prostate cancer [Li et al., 2005]. Benign prostatic hyperplasia (BPH) is a common, progressive with age, disease which occurs in approximately $50 \%$ of men aged about 60 years old, $90 \%$ of men aged about 90 years of age resulting in a serious medical and social problem. The 
consequence is progression of urethral stenosis, and thus the appearance of troublesome symptoms in the lower part of the urinary tract (LUTS - lower urinary tract symptoms), affecting the quality of life [Fong., 2004].

Currently, the first-line pharmacological treatment options in men with BPH, moderate to severe LUTS and as adjuvant therapy of androgen-dependent prostate cancer the 2nd classes of drugs, mainly alpha-adrenergic blockers (alpha-blockers) and 5alpha-reductase inhibitors (5-ARIs; azasteroids - finasteride, dutasteride) are indicated [Gravas et al., 2010; Nickel et al., 2010; Elterman et al., 2010]. Steroid 5a-reductase 2 (SRD5A2) catalyzes the conversion of testosterone to the more potent androgen, $\mathrm{DHT}$, in the prostate [Luo et al., 2003]. Decreased expression of SRD5A2 has been observed in prostate cancer. Many authors indicate that there is an association of prostate cancer with reduced 5a-reductase enzymatic activity as a result of remarkably decreased expression of the SRD5A2 gene [Luo et al., 2003].

The usage of classical pharmacological treatment causes however the risk of a number of side effects i.e.: orthostatic hypertony, tachycardia (alpha-blockers), abnormal ejaculation, decreased volume of ejaculate, erectile dysfunction (5-ARIs) [Lepor, 2011]. They have a proven impact on reducing prostate size by modifying the concentration of DHT acting on epithelial cells and core. Influence of the size of the prostate 5 alpha reductase inhibitors results of blocking the enzyme 5-alpha steroid reductase - converting the testosterone $(\mathrm{T})$ to dihydrotestosterone (DHT), the active form responsible for the growth, proliferation and development of the prostate and to facilitate atrophy and apoptosis [Gravas et al., 2010]. However, the necessity of their long application and, consequently, the emergence of a number of side effects forced researchers to search for new pharmacologically active molecules, including those contained in the plant extracts.

\section{Phytotherapy of BPH and PC}

Indeed, herbal medicines are used the most: they have an established position in prophylaxis and symptomatic treatment and prevention of urological diseases [Lowe et al., 2008; Macdonald et al., 2012; Kim et al., 2012; Morán et al., 2013]. One of the best examples of modern phytotherapy is the treatment of BPH [Azimi et al., 2012; Morán et al., 2013]. Although plant materials used for the prevention and treatment of BPH, PC and LUTS are based mainly on the tradition of natural medicine, there is growing number of preclinical and clinical studies attempting to determine the safety and efficacy of preparations of plant origin [Kim et al., 2012; Morán et al., 2013] . The most popular is Serenoa repens (saw palmetto) [Macdonald et al., 2012], also Pygeum africanum (african plum), Cucurbita pepo (pumpkin), as well as Urtica dioica, Zea mays, Secale cereale, Hypoxis rooperi (south African grass) and other [Wilt et al., 2000; Cristoni et al., 2000; Steenkamp, 2003; PDR, 2007; Lowe, 2008; Dedhia et al., 2008; Wehrberger et al., 2012; Azimi et al., 2012; Kim et al., 2012]. For them mostly antiproliferative effects, normalization of steroid hormones disturbance (antiandrogenic, antiestrogenic effects), decreasing the level of androgens transporter proteins (mostly SHBG), relaxation of smooth muscle in prostate, bladder gland and anti-inflammatory or antioxidant properties have been described [Lowe et al., 1999; Wilt et al., 2000; Dreikorn, 2002; PDR, 2007; Azimi et al., 2012; Morán et al., 2013].

Their molecular mechanism of action is still not fully understood, however, it is well known that it is mainly multidirectional, and is based primarily on the change in the enzymatic activity of $5 \alpha$-steroid reductase, aromatase or lipooxygenases enzymes, protein growth factors, androgen (AR), estrogen (ER) receptors, as well as $\alpha$-adrenergic and muscarinic receptors activities or by the promoting of the proteins regulating apoptosis in proliferating prostate cells (i.e. caspases, $\mathrm{Bax} / \mathrm{Bcl} 2$ proteins) [Madersbacher et al., 2008; Dedhia et al., 2008; Kujawski et al., 2010; Wehrberger et al., 2012; Kim et al., 2012; Morán et al., 2013]. Several in vitro studies confirmed especially the inhibitory activity of plant extracts on steroid $5 \alpha$-reductase activity, resulting in a decrease of DHT in the cells, without causing the increased expression levels of prostate specific antigen (PSA) [Delos et al., 1994; Di Silverio et al., 1998; Hsieh et al., 2002; Hill et al., 2004; ]. Also Yang and coworkers confirmed the induction of apoptosis in several cancer cell lines (LNCaP, PC-3, DU145) by extract from fruits of Serenoa repens manifested by increased expression of proteins "guardians of apoptosis" p21waf1 and p53 [Yang, 2007]. In our studies we have shown that administration of Epilobium angustifolium aqueous extract caused a decrease in the level of expression of selected genes involved in the pathology of BPH in prostate lobes in rats and a small pro-androgenic effect [Kujawski et al., 2010; Kujawski et al., 2013; Kujawski et al., 2014; not fully-published data], the natural chemopreventive agents to counteract these cancer-related epigenetic alterations by influencing the activity or expression of DNA methyltransferases and histone modifying enzymes. 
According to current state of knowledge chemopreventive agents that target the epigenome in cancer cells include so-called micronutrients (folate, retinoic acid, and selenium compounds), butyrate, polyphenols from green tea, apples, coffee, black raspberries, and other dietary sources, genistein and soy isoflavones, curcumin, resveratrol, dihydrocoumarin, nordihydroguaiaretic acid (NDGA), lycopene, anacardic acid, garcinol, some compounds from Allium species and several cruciferous vegetables, including indol-3-carbinol (I3C), diindolylmethane (DIM), sulforaphane, phenylethyl isothiocyanate (PEITC), phenylhexyl isothiocyanate (PHI), diallyldisulfide (DADS) and allyl mercaptan (AM), cambinol, and relatively unexplored modulators of histone lysine methylation. Up to date the above data are based mainly on in vitro assays, and results of animal models or human intervention studies are limited that demonstrate the functional relevance of epigenetic mechanisms for health promoting of BPH and/or PC preventive efficacy of natural products [Ho et al., 2011; Gerhauser, 2013; Chiam et al., 2014]. Furthemore, literature data does not provide so far the complex information on the molecular mechanism of action of extracts based on above mentioned plant substances in prostate gland.

Molecular aspects of phytotherapy of prostate disease progression

Epigenetics refers to the study of heritable changes in gene expression without any changes in DNA sequence. Epigenetic processes involve three interacting molecular mechanisms: DNA methylation, modification of histones in chromatin and RNA-mediated regulation of gene expression [Peedicayil, 2006]. These patterns are known to be reversible and vary with age as well as varying from tissue to tissue, since an individual has multiple epigenomes. The importance of epigenetics in clinical medicine has been increasingly appreciated, both in the pathogenesis of single-gene disorders and common diseases. Among the common diseases, except of cancer, little is known at present regarding the role of epigenetics in the pathogenesis of these diseases [Feinberg, 2007]. One of the most important epigenetic aberration is DNA methylation, which is the addition of a methyl group to the 5 -carbon of cytosine in $\mathrm{CpG}$ sequences, catalyzed by DNA methyltransferases (DNMTs). Methylcytosine residues are often found in short stretches of $\mathrm{CpG}$-rich regions (i.e., $\mathrm{CpG}$ islands) that are $0.5-2 \mathrm{~kb}$ long and found in the $5^{\prime}$ region of approximately $60 \%$ of genes [Gardiner-Garden and Frommer, 1987].
The development of pathologically changed prostate cells proliferation involves many factors, including genetic alterations, such as mutations, and epigenetic changes, appear to contribute to the transformation and progression of prostate cancer. Studies on cell lines focused so far on a number of genes, but the most important for the epigenetic changes and their relation to the development of prostate proliferation, especially the prostate cancer, are classified into four groups: hormonal response genes (androgen receptor (AR), Steroid 5- $\alpha$-reductase type 2 (SRD5a2), estrogen receptors (ERs): ER alpha (ESR1) and ER beta (ESR2)), cell cycle control genes (RB1), cell invasion genes (CD44, adenomatous polyposis coli (APC)) and DNA damage repair genes (glutathione S-transferase Pi (GSTP1)).

In our opinion it is very important to investigate whether plant extract has a direct impact on changes in the level of methylation and expression of selected genes, which are modifications influencing development of prostate cancer.

\section{Hormonal response genes}

In the literature there are few studies evaluating the changes in the methylation profile of gene sequences in the pathogenesis of hormone-dependent prostate in vivo. There is a growing number of in vitro studies concerning this problem. Current state of knowledge presents a positive relationship between epigenetics modifications and expression level of androgen receptor (AR) gene in prostate cancer development. Aberrant hypermethylation in the AR promoter region may play a critical role in AR expression in rat prostate cancers [Takahashi et al., 2002]. It is well known that hypermethylation is a potential transcriptional regulatory mechanism in prostate cancer in an approximately $\sim 1.5-\mathrm{kb}$ region of $\mathrm{CpG}$ island in the $\mathrm{AR}$ gene in the AR expression-negative cell lines Du145, DuPro, TSUPRI, and PPC1 [Jarrard et al., 1998], which has been not detected in non-tumor prostate epithelial cells [Jarrard et al., 1998; Nakayama et al., 2000]. Takahashi et al. have not observed the AR mRNA expression in any of the rat prostate cancer model or human cancer cell lines (PLS10, 20, and 30) and all of the examined rat prostate and seminal vesicle cancers demonstrated hypermethylation at these $\mathrm{CpG}$ sites [Takahashi et al., 2002]. The authors showed that methylation of CpG sites at $-312,-274,-9$, and -1 nucleotides upstream of the transcriptional initiation site correlated well with AR mRNA expression in rat prostate.

Therefore, in our opinion, the biological changes of the methylation-mediated AR inactivation in prostate 
occurring in BPH as a potential source of cancerous development and the effects of several plant extracts on the level of expression of AR gene and methylation status of $\mathrm{CpG}$ sites at $-312,-274,-9$, and -1 nucleotides upstream of the transcriptional initiation site should be investigated.

Estrogen receptors (ERs) A and B have been identified in normal and cancerous prostate tissue [Karr et al., 1979]. Hypermethylation of cytosine-rich areas in promoters of ESR genes seem to be associated with the transcriptional inactivation and also has been detected frequently in cancer [Esteller et al., 2001]. ESR receptor genes appear to be inactivated by $\mathrm{CpG}$ methylation in prostate cancer tissue and cell lines [Sasaki et al., 2002]. The extent of ESR1 and ESR2 promoter methylation is significantly less in the BPH than in prostate tumors [Li et al., 2000], indicating that prostate cancer induces ESR gene hypermethylation.

The analysis of the literature data found no studies on changes in the level of methylation in the promoter of ESR1 and ESR2 in the prostate of the rat. The most analyzed regions in these genes are ER1 promoter region (spanning -186 to -45 upstream of transcription start site) and ER2 promoter region (spanning -625 to -392 , important regulatory region) [Doshi et al., 2011]. It is very important to evaluate the methylation status of these regions in ESR1 and ESR2 genes in, for example, in vivo BPH pathogenesis model under the influence of herbal extracts.

There are many published data concerning the methylation status of SRD5A2 gene in $\mathrm{BPH}$ and PC and its influence on the expression level as well as if any of the bioactive compounds of analyzed in this project extracts would be responsible for the epigenetic regulation of studied hormonally dependent genes. Blanchard et al analysed the promoter region of the 5alpha-reductase type 1 gene and observed that the high percentage of $\mathrm{G}+\mathrm{C}$ which accounted for $61.3 \%$ of the nucleotides in the region from -1000 to +1 ; numerous CpG were present, and the CpG observed/ CpG expected ratio was 0.76 for this $1 \mathrm{~kb}$ window. Further, within a 500 bp region (from -500 to +1 ), no less than 11 potential Sp1 binding sites (GC and GT boxes) were found with sequence homology very close to the Sp1 consensus sequence. Based on the above mentioned results, in our opinion, the evaluation of such 500 bp length fragment against changes in the level of methylation, their relationship to the level of gene expression of 5alpha-reductase and changes in methylation and expression under the influence of crucial in the phytotherapy of BPH/PC plant extracts could be a very important step enabling an assessment of their mechanism of action and therefore safety and efficacy with a comedication with currently used drugs of first choice.

\section{DNA damage repair genes}

Hypermethylation of genes involved in DNA damage repair, has been reported in prostate cancer [Li et al., 2005]. Methylation changes in the glutathione S-transferase P1 (GSTP1) promoter are the most frequent alterations in prostate cancer development. Many scientific data indicated that hypermethylation of GSTP1 is involved in intracellular detoxification reactions and in loss of gene expression. Hypermethylation has been found in $>90 \%$ of prostatic carcinomas, including early disease stages, and has not been detected in normal tissues [Goessl, 2000.].

The comparison between methylation status of DNA damage repair genes in benign prostatic and prostate cancer cell lines showed that frequencies of the methylation level in prostate cancer were higher than in BPH [Yamanaka et al., 2003].

A literature analysis shows no studies on the analysis of methylation in the promoter of the gene GSTP1 in rat prostate. Therefore, in order to obtain a better understanding of the molecular mechanism of action of plant extracts in prostate gland, we postulate, based on studies presented by Nakayama et al., that the investigation of the methylation status of promoter region (a region extending in human GSTP1 from a pentad [ATAAA]n repeat sequence located at -414 of the GSTP1 transcription start site to an area between +296 and +625 of the gene) and the expression level of this gene could be a very promising course .

\section{Cell cycle control genes}

Retinoblastoma (RB1) protein plays a crucial role in regulation of the cell cycle and has been identified in many tumor types as a tumor suppressor gene [Lee et al.,1987]. According to our knowledge there is only one published study resulting in the information that loss of RB1 expression correlated with homozygous deletion or promoter hypermethylation in histologically heterogeneous prostate carcinomas, which indicate that hypermethylation is correlated with the loss of gene function [Konishi et al., 2002]. The analysis of the literature data found no studies on the analysis of methylation in the promoter of the gene of RB1 in rat prostate. Therefore, the authors based on studies presented by Stirzaker et al. investigated the methylation status of the promoter region in 185-206 bp upstream 
of the initial codon and contains putative binding sites for transcription factors RBF-1, Sp1, ATF and EF2, in gene RB1 in rat prostate. It is very important to verify the methylation status and expression level of RB1 in the pathogenesis of $\mathrm{BPH}$ in prostate gland (in vivo models, clinical samples), especially under the influence of selected plant extracts. Such mechanism of action in prostate cells is still unknown. Therefore, these aspects should be more complex studied.

\section{Cell invasion genes}

The APC gene encodes a protein with multiple cellular functions and interactions, including roles in signal transduction in the Wnt-signalling pathway, mediation of intercellular adhesion, stabilization of the cytoskeleton and possibly regulation of the cell cycle and apoptosis [Fearnhead and all., 2001]. Methylation in APC promoter was associated with an increased risk of prostate cancer-specific mortality and promoter methylation in APC was identified as a marker for prostate cancer progression [Richiardi et al., 2009]. However such studies were performed so far in in vitro cell cultures, thus there are no published data concerning the methylation status of APC gene in prostate gland. CD 44 is also an important integral membrane protein receptor, playing a crucial role in cell-cell and cell-matrix interactions, and has been implicated in tumor growth and migration [Naor et al., 1997]. Some studies demonstrated that loss of CD44 expression correlates with methylation and was associated with increased grade and pathological stage of prostate cancer [Verkaik et al., 2000]. Such mechanism of action of plant origin bio-active compounds in prostate cells is still unknown. Therefore, these aspects require further comprehensive studies.

\section{Conclusions}

Epigenetic modifications ongoing in pathophysiologically changed prostate gland in response of pathophysiological process may be a crucial factors in the progression of prostate diseases (BPH, PC). Although the pharmacological activities of plant origin substances have been described, their above mentioned epigenetic mechanisms of action are still unknown. The authors suggest that the knowledge of epigenetic modifications presented in this paper introduces the new point of view concerning the possibility of action of plant substances used in prevention and symptomatic treatment of $\mathrm{BPH}$ and prostate cancer. Thus, identification of the epigenetic modifications involved on the one hand in the development and progression of BPH/PC, on the other influencing the efficacy and safety of potential phytotherapeutics will be helpful in identifying its novel therapeutic strategy.

\section{Acknowledgements}

\section{Conflict of interest statement}

The authors declare that there is no conflict of interest in the authorship or publication of contribution.

\section{Funding sources}

There are no sources of funding to declare.

\section{References}

1. Cohen MB, Rokhlin OW. Mechanisms of Prostate Cancer Cell Survival After Inhibition of AR Expression. Journal of Cellular Biochemistry. 2009;106:363-371.

2. Delos S, lehle C, Martin PM. Raynaud JP. Inhibition of the activity of 'basic' 5 alpha-reductase (type 1) detected in DU 145 cells and expressed in insect cells. J Steroid Biochem Mol Biol. 1994;48(4):347-52.

3. Di Silverio F, Monti S, Sciarra A, Varasano PA, Martini C, Lanzara S, D'Eramo G, Di Nicola S, Toscano V. Effects of long-term treatment with Serenoa repens (Permixon) on the concentrations and regional distribution of androgens and epidermal growth factor in benign prostatic hyperplasia. Prostate. 1998;37(2):77-83.

4. Doshi T, Mehta SS, Dighe V, Balasinor N, Vanage G. Hypermethylation of estrogen receptor promoter region in adult testis of rats exposed neonatally to bisphenol $\mathrm{A}$. Toxicology. 2011;18;289(2-3):74-82.

5. Esteller M, Corn PG, Baylin SB, Herman JG. A gene hypermethylation profile of human cancer. Cancer Res 2001; 61:3225-9.

6. Fearnhead NS, Britton MP, Bodmer WF. The ABC of APC. Hum Mol Genet. 2001;10(7):721-33.

7. Feinberg AP. Phenotypic plasticity and the epigenetics of human disease. Nature. 2007;447:433-440.

8. Fong YK., Marihart S., Harik M., Djavan B. Preventing progression in men with mild symptoms of benign prostatic hyperplasia: a potential role for phytotherapy. Rev Urol. 2004;6(4):187-92.

9. Gao AC, Lou W, Dong JT, Isaacs JT. CD44 is a metastasis suppressor gene for prostatic cancer located on human chromosome 11p1. Cancer Res. 1997;57:846-849.

10. Gardiner-Garden M, Frommer M. CpG islands in vertebrate genomes. J Mol Biol. 1987;196:261-82.

11. Gerhauser C. Cancer chemoprevention and nutriepigenetics: state of the art and future challenges. Top Curr Chem. 2013;329:73-132.

12. Goessl C, Krause H, Mueller M, Heicappell R, Schrader $M$, Sachsinger J, Miller K. Fluorescent methylation-specific polymerase chain reaction for DNA-based detection of prostate cancer in bodily fluids. Cancer Res. 2000;60:4159.

13. Gravas S, Oelke M. Current status of 5alpha-reductase inhibitors in the management of lower urinary tract symptoms and BPH. World J Urol. 2010;28:9-15. 
14. Hill B, Kyprianou N. Effect of permixon on human prostate cell growth: lack of apoptotic action. Prostate. 2004;61(1):73-80.

15. Ho E, Beaver LM, Williams DE, Dashwood RH. Dietary factors and epigenetic regulation for prostate cancer prevention. Adv Nutr. 2011;2(6):497-510.

16. Hsieh TC, Wu JM. Mechanism of action of herbal supplement PC-SPES: elucidation of effects of individual herbs of PC-SPES on proliferation and prostate specific gene expression in androgen-dependent LNCaP cells. Int J Oncol. 2002;20(3):583-8.

17. Chiam K, Ricciardelli C, Bianco-Miotto T. Epigenetic biomarkers in prostate cancer: Current and future uses. Cancer Lett. 2014;342(2):248-56.

18. Jarrard DF, Bova GS, Ewing CM, Pin SS, Nguyen SH, Baylin SB, et al. Deletional, mutational, and methylation analyses of CDKN2 (p16/MTS1) in primary and metastatic prostate cancer. Genes Chromosomes Cancer. 1997;19:90-6.

19. Jarrard DF, Kinoshita H, Shi Y, Sandefur C, Hoff D, Meisner LF, Chang C, Herman JG, Isaacs WB, Nassif N. Methylation of the androgen receptor promoter $\mathrm{CpG}$ island is associated with loss of androgen receptor expression in prostate cancer cells. Cancer Res. 1998;58:5310-15.

20. Kang GH, Lee S, Lee HJ, Hwang KS. Aberrant CpG island hypermethylation of multiple genes in prostate cancer and prostatic intraepithelial neoplasia. J Pathol 2004;202:233-40.

21. Karr JP, Wajsman Z, Madajewicz S, Kirdani RY, Murphy GP, Sandberg AA. Steroid hormone receptors in the prostate. J Urol 1979;122:170-5.

22. Koh J, Enders GH, Dynlacht BD, Harlow E. Tumour-derived p16 alleles encoding proteins defective in cell-cycle inhibition. Nature 1995;375:506-10.

23. Konishi N, Nakamura M, Kishi M, Nishimine M, Ishida E, Shimada K. Heterogeneous methylation and deletion patterns of the INK4a/ARF locus within prostate carcinomas. Am J Pathol 2002;160:1207-14.

24. Konishi N, Nakamura M, Kishi M, Nishimine M, Ishida E, Shimada K. DNA hypermethylation status of multiple genes in prostate adenocarcinomas. Jpn J Cancer Res 2002;93:767-73.

25. Kujawski R, Bartkowiak-Wieczorek J. Wybrane właściwosci biologiczne surowców zielarskich z rodzaju Epilobium z uwzglednieniem zagadnień profilaktyki schorzeń prostaty w okresie andropauzy. Postep. Farm. 2012;1:16-22.

26. Kujawski R, Bartkowiak-Wieczorek J, Bogacz A, Karasiewicz M, Mikołajczak Pt, Czerny B, Mrozikiewicz PM. SRC kinase mRNA transcription changes in testosterone-induced rat ventral prostate lobes under the influence of Epilobium angustifolium extract. Herba Pol. 2013;59(4):60-71.

27. Kujawski R, Bartkowiak-Wieczorek J, Karasiewicz M, Bogacz A, Mikołajczak P, Czerny B, Mrozikiewicz PM. Influence of Epilobium angustifolium extract on $5 \alpha$-reductase type 2 and MAPK3 kinase gene expression in rats prostates. Herba Pol. 2013;59(4):72-85.

28. Kujawski R, Bogacz A, Bartkowiak-Wieczorek J, Karasiewicz M, Mikołajczak Pt, Mrozikiewicz-Rakowska B, Wolski H, Czerny B, Grześkowiak E, Mrozikiewicz PM. Effect of Epilobium angustifolium and Serenoa repens extracts on regulation of non-genomic signaling pathway of kinases. Ginek Pol. 2014;85:278-282.
29. Kujawski R, Mrozikiewicz PM, Bogacz A, Cichocka J, Mikołajczak Pt, Czerny B, Bobkiewicz-Kozłowska T, Grześkowiak E. Influence of standardized extract of Epilobium angustifolium on estrogen receptor alpha and beta expression in in vivo model. Ginekol Pol. 2010;81(8):600-5.

30. Lee WH, Bookstein R, Hong F, Young LJ, Shew JY, Lee EY. Human retinoblastoma susceptibility gene: cloning, identification, and sequence. Science 1987;235:1394-9.

31. Lepor H. Medical Treatment of Benign Prostatic Hyperplasia. Rev Urol. 2011;13(1):20-33.

32. Li LC, Carroll PR, Dahiya R. Epigenetic Changes in Prostate Cancer: Implication for Diagnosis and Treatment. Journal of the National Cancer Institute, 2005, Vol. 97, No. 2, January 19.

33. Li LC, Chui R, Nakajima K, Oh BR, Au HC, Dahiya R. Frequent methylation of estrogen receptor in prostate cancer: correlation with tumor progression. Cancer Res. 2000;60:702-706.

34. Lowe FC. The Role of Serenoa repens in the Clinical Management of Lower Urinary Tract Symptoms Due to Benign Prostatic Hyperplasia. Eur Urol Suppl. 2009;8:894-7.

35. Luo J, Dunn TA, Ewing CM, Walsh PC, Isaacs WB. Decreased Gene Expression of Steroid 5 Alpha-Reductase 2 in Human Prostate Cancer: Implications for FinasterideTherapy of Prostate Carcinoma. The Prostate. 2003;57: $134-139$.

36. Macdonald R, Tacklind JW, Rutks I, Wilt TJ. Serenoa repens monotherapy for benign prostatic hyperplasia (BPH): an updated Cochrane systematic review. BJU Int. 2012;109(12):1756-61.

37. Nakayama T, Watanabe $M$, Suzuki $H$, Toyota M, Sekita $N$, Hirokawa Y, Mizokami A, Ito H, Yatani R, Shiraishi T. Epigenetic Regulation of Androgen Receptor Gene Expression in Human Prostate Cancers. Laboratory Investigation. 2000, Vol. 80, No. 12, p. 1789.

38. Naor D, Sionov RV, and Ish-Shalom D. CD44: Structure, function, and association with the malignant process. Adv Cancer Res. 1997;71:241-319.

39. Nguyen TT, Nguyen CT, Gonzales FA, Nichols PW, Yu MC, Jones PA. Analysis of cyclin-dependent kinase inhibitor expression and methylation patterns in human prostate cancers. Prostate 2000;43:233-42.

40. Nickel JC, Méndez-Probst CE, Whelan TF, Paterson RF, Razvi H. 2010 Update: Guidelines for the management of benign prostatic hyperplasia. Can Urol Assoc J. 2010;4(5):310-6.

41. Peedicayil J. Epigenetic therapy - a new development in pharmacology. Indian J. Med. Res. 2006;123(1):17-24.

42. Richiardi L, Fiano V, Vizzini L, De Marco L, Delsedime L, Akre O, Tos AGMerletti F. Promoter Methylation in APC, RUNX3, and GSTP1 and Mortality in Prostate Cancer Patients. JCO. 2009;27(19):3161-3168.

43. Sakai T, Toguchida J, Ohtani N, Yandell DW, Rapaport JM, Dryja TP. Allele-specific hypermethylation of the retinoblastoma tumor-suppressor gene. Am J Hum Genet 1991;48:880-8.

44. Sasaki M, Tanaka Y, Perinchery G, Dharia A, Kotcherguina I, Fujimoto S, Dahiya R. Methylation and Inactivation of Estrogen, Progesterone, and Androgen Receptors in Prostate Cancer. Journal of the National Cancer Institute. 2002, Vol. 94, No. 5, March 6. 
45. Steenkamp V. Phytomedicines for the prostate.Fitoterapia. 2003 Sep;74(6):545-52.

46. Stirzaker C, Millar DS, Paul CL, Warnecke PM, Harrison J, Vincent PC, et al. Extensive DNA methylation spanning the $\mathrm{Rb}$ promoter in retinoblastoma tumors. Cancer Res 1997;57:2229-37.

47. Takahashi S, Inaguma S, Sakakibara M, Cho YM, Suzuki S, Ikeda Y, Cui L, Shirai T. DNA methylation in the androgen receptor gene promoter region in rat prostate cancers. Prostate. 2002 Jun 1;52(1):82-8.

48. Tsuchiya T, Tamura G, Sato K, Endoh Y, Sakata K, Jin Z, Motoyama T, Usuba O, Kimura W, Nishizuka S, Wilson KT, James SP, Yin J, Fleisher AS, Zou T, Silverberg SG, Kong D, Meltzer SJ. Distinct methylation patterns of two APC gene promoters in normal and cancerous gastric epithelia. Oncogene. $2000 \mathrm{Jul}$ 27;19(32):3642-6.

49. Verkaik NS, van Steenbrugge GJ, van Weerden WM, Bussemakers MJ, van der Kwast TH. Silencing of CD44 expression in prostate cancer by hypermethylation of the D44 promoter region. Lab Invest. 2000;80:1291-1298.

50. Yamanaka M, Watanabe M, Yamada Y, Takagi A, Murata T, Takahashi H, Suzuki H, Ito H, Tsukino H, Katoh T, Sugimura Y, Shiraishi T. Altered methylation of multiple genes in carcinogenesis of the prostate. Int J Cancer. 2003 Sep 1;106(3):382-7.

51. Yang $Y$, Ikezoe $T$, Zheng $Z$, Taguchi $H$, Koeffler HP, Zhu WG. Saw Palmetto induces growth arrest and apoptosis of androgen-dependent prostate cancer LNCaP cells via inactivation of STAT 3 and androgen receptor signaling. Int J Oncol. 2007;31(3):593-600.

Acceptance for editing: 2015-04-29 Acceptance for publication: 2015-05-28

Correspondence address: Joanna Bartkowiak-Wieczorek Laboratory of Experimental Pharmacogenetics, Department of Clinical Pharmacy and Biopharmacy, Poznan University of Medical Sciences, Poland phone: +48512322 877 e-mail: joanna@wieczorek.net.pl 